\title{
Carbon-coated fluorinated graphite for high energy and high power densities primary lithium batteries
}

\author{
Q. Zhang* ${ }^{1}$, S. D'Astorg ${ }^{1}$, P. Xiao ${ }^{2}$, X. Zhang ${ }^{3}$ and L. Lu ${ }^{2}$
}

1. Department of Materials, Cranfield University, Cranfield, Bedfordshire, MK43 OAL, UK

2. Department of Mechanical Engineering, National University of Singapore, Singapore, 117576.

3. Ultralife Corporation, Ultralife Batteries Brand, 2000 Technnology Parkway, Newark, NY 14513, USA

* Corresponding author: q.zhang@cranfield.ac.uk

\begin{abstract}
The electrochemical performances of fluorinated graphite have been improved by coating a uniform carbon layer on commercial $\mathrm{CF}_{\mathrm{x}}(\mathrm{x}=1)$ powder used as cathode material in lithium battery. In comparison with the cell using un-coated $\mathrm{CF}_{\mathrm{x}}$ as cathode, the cell using carbon coated $\mathrm{CF}_{\mathrm{x}}$ cathode has a higher energy density and higher power density, particularly at higher discharge current rates (1C above). This is because the conductive carbon coating provides the exterior connectivity between particles for facile electron conduciton, resulting in high rate performance.
\end{abstract}

\section{Introduction}

Primary lithium batteries are commonly used for many applications such as cameras, electrical lock, electronic counter, electronic measurement equipment, emergency power source, memory back-up, military and implantable medical devices. These applications require power sources with high energy densities, good reliability, safety and long life. $\mathrm{Li}$ /graphite fluoride $\left(\mathrm{CF}_{\mathrm{x}}\right)$ cells are known to have the highest theoretical capacity when 
compared to other primary lithium batteries such as $\mathrm{Li} / \mathrm{SOCl}_{2}$ and $\mathrm{Li} / \mathrm{MnO}_{2}$ batteries. The overall discharge reaction of a $\mathrm{Li} / \mathrm{CF}_{\mathrm{x}}$ cell is expressed as " $C F_{x}+x L i \rightarrow C+x L i F$ ". According to this reaction, the specific capacity of this cell increases with the increase of fluorine content, $x$ [1]. The theoretical specific discharge capacity Qth, expressed in $\mathrm{mAhg}^{-1}$, is given by Eq. (1) [2].

$$
Q_{t h}=\frac{x F}{3.6(12+19 x)}
$$

where $F$ is the Faraday constant $(96485$ Coulomb/mol) and 3.6 is a unit conversion constant. Theoretically, a $\mathrm{CF}_{\mathrm{x}}$ with $\mathrm{x}=1$ has a specific capacity of $865 \mathrm{mAhg}^{-1}$, about twice that of $\mathrm{SOCl}_{2}$ currently used in primary $\mathrm{Li} / \mathrm{SOCl}_{2}$ batteries. Therefore, carbon fluorides $\mathrm{CF}_{\mathrm{x}}$ with $\mathrm{x}$ close to unity have been actively studied as cathode materials in high energy density lithium batteries [3-4]. Two types of synthesis are usually performed to form graphite fluorides: high temperature synthesis at $600{ }^{\circ} \mathrm{C}$ and low temperature synthesis at $<100{ }^{\circ} \mathrm{C}$. The commercial $\mathrm{CF}_{\mathrm{x}}$ materials are normally synthesized at high temperature. The most important features of the $\mathrm{Li} / \mathrm{CF}_{1}$ (synthesized at high temperature) batteries are: high average operating voltage (around $2.4 \mathrm{~V}$ vs. $\mathrm{Li}^{+} / \mathrm{Li}$ ), long shelf life (> 10 years at room temperature), stable operation and wide operating temperatures (-40 to $\left.170{ }^{\circ} \mathrm{C}\right)[1]$. In most non-aqueous liquid electrolytes, $\mathrm{CF}_{1}$ cathode materials obtained at low temperature has an open circuit voltage $(\mathrm{OCV})$ of $3.2-3.5 \mathrm{~V}$ vs. $\mathrm{Li}^{+} / \mathrm{Li}$. However, discharge voltage of a real $\mathrm{Li} / \mathrm{CF}_{\mathrm{x}}$ cell $(\mathrm{x}=1)$ is much lower than this value, showing significant polarization [5] and average discharge voltage is lower for more covalent materials [6]. One reason for this high polarization is the low electronic conductivity of strongly covalent $\mathrm{CF}_{1}$ materials. This kinetic limitation leads to the batteries being able to 
sustain only low to medium range discharge currents. In order to develop such batteries for new applications such as for soldier portable power sources [7] and for space long term exploratory missions, the range of achievable discharge currents should be extended, so as to increase the power density. To reach this goal, many efforts have been made. For example, Yazami et al. [1-2] synthesized a series of subfluorinated $\mathrm{Li} / \mathrm{CF}_{\mathrm{x}}(\mathrm{x}<$ 1) cells with much improved power capability. However, their success was made at a cost of specific capacity.

In this study, we report the improvement of current density $(2 \mathrm{C})$ of $\mathrm{Li} / \mathrm{CF}_{\mathrm{x}}$ cell by coating a carbon layer on the commercial $\mathrm{CF}_{\mathrm{x}}$ materials aimed at increasing the electrical conductivity of $\mathrm{CF}_{\mathrm{x}}$ cathode materials.

\section{Experimental}

\subsection{Sample preparation}

Fluorinated graphite $(\mathrm{CF})$ powder with particle size of 6-10 $\mu \mathrm{m}$ was provided by Lodstar and used as the active cathode material. Polyvinylidene difluoride (PVDF) (Sigma, UK) material was used as the carbon precursor. The PVDF was first mixed with acetone and formed a slurry, and then the CF powder was well added to the PVDF-acetone slurry and stirred to form a homogeneous mixture and then allowed to be gradually dried. Finally, the PVDF-graphite mixture was heat-treated at various temperature up to $600{ }^{\circ} \mathrm{C}$ in nitrogen for $2 \mathrm{hrs}$, the PVDF converted to form a very thin layer of carbon coatings on each individual CF particle's surface. PVDF acts as the carbon source resulting in a uniform carbon coating on $\mathrm{CF}_{\mathrm{x}}$ particles.

\subsection{Characterization}


X-ray diffraction (XRD) patterns were obtained using a Siemens D5005 diffractometer with $\mathrm{Cu} K \alpha$ radiation and a Goebel mirror. Scanning electron microscopy (S-FEG SEM) and EDX elemental analysis were performed on a Philips XL30.

\subsection{Electrochemical study}

Typical electrodes are composed of graphite fluoride (with or without carbon pre-coating, $75 \%$ by weight, w/w), carbon black $(15 \%, w / w)$ to insure electronic conductivity and PVDF $(10 \%, \mathrm{w} / \mathrm{w})$ as binder. The mixture was rolled into a thin film onto an aluminum foil current collector disk of $10 \mathrm{~mm}$ in diameter. Finally, the disk was dried in a vacuum oven at $120{ }^{\circ} \mathrm{C}$ for $12 \mathrm{hrs}$, to remove traces of water. The mass of active material was 0.28-0.48 mg for all the experiments. A two electrodes cell was used (Swagelok cell type), where lithium was used as both reference and counter electrode. A Celgard separator wet with 1.0M LiPF6 EC:DEC (1:1 by weight) electrolyte, was sandwiched between the composite electrode and a lithium metal foil. The cells were assembled in an argon filled dried glove box. Relaxation was performed for at least $5 \mathrm{hrs}$ until open circuit voltage being stable. Galvanostatic discharges were carried out on a Neware battery test station at room temperature $\left(24^{\circ} \mathrm{C}\right)$, where $1 \mathrm{C}$ rate equals $865 \mathrm{~mA} / \mathrm{g}$. Discharge capacities detailed in this article have been obtained for a cell cut-off of $1.5 \mathrm{~V}$.

\section{Results and discussion}

The color of commercial $\mathrm{CF}_{\mathrm{x}}$ is white-grey and the carbon-coated $\mathrm{CF}_{\mathrm{x}}$ is black. The XRD patterns (not shown here) for $\mathrm{CF}_{\mathrm{x}}$ and carbon-coated $\mathrm{CF}_{\mathrm{x}}$ are identical, indicating that carbon coating does not change the basic crystal structure of $\mathrm{CF}_{\mathrm{x}}$. Fig. 1 shows the SEM images of both un-coated and coated $\mathrm{CF}_{\mathrm{x}}$. The particle sizes of both samples range from 
2-6 $\mu \mathrm{m}$. The carbon coated $\mathrm{CF}_{\mathrm{x}}$ powders tend to aggregate, which may be caused by the interaction of static electricity of small carbon particles coated on the surface of $\mathrm{CF}_{\mathrm{x}}$. The morphology of two samples seems to differ. The un-coated $\mathrm{CF}_{\mathrm{x}}$ particles (Fig.1 a and b) have a smoother surface with sharper edges in comparison with coated $\mathrm{CF}_{\mathrm{x}}(\mathrm{Fig} .1 \mathrm{c}$ and d). The elemental analysis by EDX on both coated and un-coated samples shows that there is a $30 \%$ increase in $\mathrm{C} / \mathrm{F}$ ratio for $\mathrm{C}$-coated $\mathrm{CF}_{\mathrm{x}}$ sample, indicating there is really a layer of carbon coated on the $\mathrm{CF}_{\mathrm{x}}$. Commercial $\mathrm{CF}_{\mathrm{x}}$ contains 39 wt $\%$ of carbon, and a $30 \%$ increase in $\mathrm{C} / \mathrm{F}$ ratio for $\mathrm{C}$-coated $\mathrm{CF}_{\mathrm{x}}$ sample indicates that the $\mathrm{C}$-coated $\mathrm{CF}_{\mathrm{x}}$ contains $\sim 50$ wt\% of carbon and all the increased carbons are on the surface of the original $\mathrm{CF}_{\mathrm{x}}$. The contribution of the fluorine from PVDF to the capacity is smaller in comparison with the contribution of the carbon from PVDF. Fig.2 represents the galvanostatic discharge curves of $\mathrm{CF}_{\mathrm{x}}$ and $\mathrm{CF}_{\mathrm{x}} / \mathrm{C}$ samples, obtained at various discharging current densities. While the discharge profile of the $\mathrm{Li} / \mathrm{CF}_{\mathrm{x}}$ cell exhibits the characteristic plateau around $2.4 \mathrm{~V}$, the discharge profile of $\mathrm{Li} / \mathrm{CF}_{\mathrm{x}} / \mathrm{C}$ shows a slightly higher voltage of $2.5 \mathrm{~V}$. An obvious increase in capacity is showed for the coated sample compared to the uncoated sample and the value of capacity of coated sample gets close to the theoretical one $(865 \mathrm{mAh} / \mathrm{g})$ while the uncoated cell delivers about $90 \%$ of theoretical capacity. The voltage of both cells shows a small and current-related delay in the beginning of discharge, and then the voltage slowly recovers to the normal voltage (2.4-2.5 V) until the discharge ends.

A widely accepted discharge reaction of $\mathrm{Li} / \mathrm{CF}_{\mathrm{x}}$ cell can be described as [8]:

Anode: $\quad x L i+x S \rightarrow x L i^{+} S+x e$ 
Cathode: $\quad C F_{x}+x L i^{+} S+x e \rightarrow C\left(L i^{+} S-F^{-}\right) x$

where $\mathrm{S}$ represents one or more solvent molecules coordinated with each $\mathrm{Li}^{+}$ion and $C\left(\mathrm{Li}^{+} S-\mathrm{F}^{-}\right)_{x}$ the graphite intercalation compound (GIC) intermediate that subsequently decomposes into the final discharge products, carbon and lithium fluoride, as shown below:

$$
C\left(\mathrm{Li}^{+} S-\mathrm{F}^{-}\right)_{x} \rightarrow \mathrm{C}+x \mathrm{LiF}+x S
$$

The cathode reaction takes place in three basic steps: (a) the diffusion of solvated lithium ions in fluorine layer, (b) the formation of GIC intermediate and (c) the injection of electrons from current collector, aluminum foil, into $\mathrm{CF}_{\mathrm{x}}$ and the dissociation of GIC intermediate. The mechanism above has shown that the slow diffusion of solvated lithium ions in the GIC intermediate layer is the controlling step in cathode reaction. The slow diffusion would not be improved by coating a carbon layer on the surface of $\mathrm{CF}_{\mathrm{x}}$ because the mechanisms in both coated and un-coated cases should remain the same. This has reflected in the results of similar specific discharge capacities and discharge voltage plateaus at low current rates in both cases. An interesting observation is the storage performance at high rates (> 1C) (Fig. 3). The specific discharge capacity for the cell using carbon-coated cathode is about $650 \mathrm{mAh} / \mathrm{g}$ at $1 \mathrm{C}$ and $370 \mathrm{mAh} / \mathrm{g}$ at $2 \mathrm{C}$ while it is only $480 \mathrm{mAh} / \mathrm{g}$ at $1 \mathrm{C}$ and $260 \mathrm{mAh} / \mathrm{g}$ at $2 \mathrm{C}$ for the cell using un-coated cathode. These results emphasize the need for optimizing the morphology in order to increase the power density. The existence of conducting carbon coating on the surface of $\mathrm{CF}_{\mathrm{x}}$ improves the particle connection and favors the electron pathway through the electrode and thus 
increases the power density, though the whole enhancement of power density is limited. This limited increase in power density of $\mathrm{CF}_{\mathrm{x}}$ by coating a carbon layer indirectly indicates that the lithium ion diffusion is a key step in controlling the cathode reaction progress. Table 1 shows the electrochemical performances of carbon-coated graphite fluoride compared with the ones of commercial graphite fluoride. The energy density and average power density of the cells obviously increase after the carbon coating, particularly at high current rates. These results are also better than those in earlier reports on primary $\mathrm{Li} / \mathrm{CF}_{\mathrm{x}}$ cells, at high rates $[1,8]$. The reason of discharging rate improvement is because the conductive carbon coating provides the exterior connectivity between particles for facile electron conduction, resulting in high rate performance. However, further optimizing the morphology of the carbon coating is needed, for example, the thickness of carbon coating, in order to obtain the maximum increase of the electron conduction. In another aspect, reducing the commercial $\mathrm{CF}_{\mathrm{x}}$ particle size from micrometer to nanometer is an efficient way to shorten the lithium ion diffusion lengths. All of these works are in progress and the results will be reported in another paper.

\section{Conclusions}

Carbon layer has been coated on the commercial $\mathrm{CF}_{\mathrm{x}}$ particles by decomposing PVDF at high temperature in $\mathrm{N}_{2}$ gas. The exterior conductive carbon coating provides connectivity for facile electron conduction, resulting in high rate performances. Carbon coating on the electrode materials thus improves the storage performance of lithium batteries and the specific discharge capacity reaches the theoretical capacity at lower discharge rates. Further optimizing the thickness of the carbon layer is needed in order to further enhance the storage performance at high current rates, and also the reduction of particle size may 
provide a shorter length of lithium ion diffusion. We believe that combination of the reduction of particle size and the exterior connectivity by optimized carbon coating would result in a high energy and high power density primary lithium battery.

\section{Acknowledgement}

Authors would like to thank Lostar, Germany for kindly providing the $\mathrm{CF}_{\mathrm{x}}$. QZ would like to thank The Royal Society for Brian Mercer Feasibility Awards (2009).

\section{References}

[1] R. Yazami, A. Hamwi, K. Guerin, Y. Ozawa, M. Dubois, J. Giraudet and F. Masin, Electrochem. Commun., 9, 1850 (2007).

[2]P. Lam and R. Yazami, J. Power Sources, 153, 354 (2006).

[3] R. Yazami, in: T. Nakajima (Ed.), Chemistry, Physics and Applications of FluorineGraphite and Fluoride-Carbon Compounds, Marcel Dekker, 1995, p. 251.

[4] N. Watanabe, Solid State ionics 1, 87 (1980).

[5] D. Linden, T.B. Reddy (Eds.), Handbook of Batteries, third ed., McGraw-Hill, 2002 (Chapter 4.9).

[6] J. Giraudet, C. Delabarre, K. Guérin, M. Dubois, F. Masin and A. Hamwi, J. Power Sources, 158, 1365 (2006).

[7] A. Suszko, R. Thompson, D. Stevens, Workshop on Carbon Fluorides for Lithium Batteries, Pasadena, CA, February 26, 2006.

[8] S. S. Zhang, D. Foster, J. Wolfenstine and J. Read, J. Power Sources, 187, 233 (2009). 